\title{
O ENSINO DE HISTÓRIA DA QUÍMICA : CONTRIBUINDO PARA A COMPREENSÃO DA NATUREZA DA CIÊNCIA
}

\author{
The teaching of History of Chemistry: \\ improving the knowledge about the nature of science
}

\author{
Maria da Conceição Marinho Oki ${ }^{1}$ \\ Edílson Fortuna de Moradillo ${ }^{2}$
}

\begin{abstract}
Resumo: Relata-se um estudo de caso que teve como objetivo explorar as potencialidades de aproximação entre História e Filosofia da Ciência da educação científica mediante utilização do ensino de História da Química. Visou-se auxiliar os alunos na compreensão da natureza da ciência e no aprendizado de conceitos químicos. O estudo envolveu a intervenção de uma professora/investigadora numa disciplina de História da Química e teve caráter exploratório, com abordagem de pesquisa qualitativa. A análise dos resultados utilizou o modelo misto, com categorias analíticas definidas a priori, que nortearam as dimensões epistemológicas de análise e a identificação de categorias emergentes, construídas a partir das respostas dos alunos a questionários abertos. Os resultados obtidos confirmaram a importância do espaço dessa disciplina para os alunos conhecerem a natureza da ciência, adquirindo concepções menos simplistas e mais contextualizadas sobre a ciência, apesar de alguma dificuldade na superação de concepções realistas ingênuas fortemente enraizadas em suas visões epistemológicas.
\end{abstract}

Palavras-chave: História e Filosofia da Ciência. Ensino de Química. Natureza da ciência.

\begin{abstract}
This paper presents the results of an exploratory study undertaken during a course of History of Chemistry for Chemistry students. The course aimed to help students to understand the nature of science and basic concepts in chemistry . The study, conducted by the course teacher, analyzed the convergence between history, and philosophy of science education and had a qualitative approach using participant observation. The data were qualitatively analyzed using a "mixed model", with two kinds of analytical categories: epistemological categories previously defined, that guided the epistemological dimensions of analysis and categories built from the answers given by the students through open questionnaires. The results show that the History of Chemistry course was important for the students to improve their knowledge about the nature of science. The students had less simplistic and more contextualized conceptions about the nature of science, in spite of the difficulty of overcoming some strongly embedded notions in the students' epistemological views.
\end{abstract}

Key words: History and Philosophy of Science. Chemistry teaching. Nature of science.

\footnotetext{
${ }^{1}$ Doutora em Educação; docente, Departamento de Química Geral e Inorgânica, Instituto de Química, Universidade Federal da Bahia. Salvador, Ba.<marinhoc@ufba.br>

${ }^{2}$ Especialista em Química; docente; Departamento de Química Geral e Inorgânica, Instituto de Química, Universidade Federal da Bahia. Salvador, Bahia. <edilson@ufba.br>

1 Instituto de Química da Universidade Federal da Bahia

Campus Universitário de Ondina

Rua Barão de Geremoabo, s/n

Ondina - Salvador, Ba

67

$40.170-290$

Ciência \&̊ Educaşão, v. 14, n. 1, p. 67-88, 2008
} 
Oki, M. C. M.; Moradillo, E. F.

\section{Introdução}

Neste artigo relata-se um estudo de caso que teve como objetivo explorar as potencialidades de aproximação entre História e Filosofia da Ciência da educação científica mediante utilização do ensino de História da Química. O estudo envolveu nossa intervenção como professora/investigadora numa disciplina de História da Química e apresentou um caráter exploratório, com abordagem de pesquisa qualitativa.

A investigação didática teve dois objetivos principais: identificar concepções prévias dos alunos sobre aspectos da natureza da ciência e avaliar tais concepções, influenciadas por uma abordagem explícita de conteúdos de Filosofia da Ciência em diversos contextos históricos. Posteriormente, trabalhou-se com a contextualização histórica de conceitos químicos para avaliar a influência de tal contextualização na compreensão desses conceitos. A pesquisa incluiu, também, o uso de materiais didáticos com conteúdos em História e Filosofia da Ciência, elaborados pela pesquisadora, cujo tema central contemplou as controvérsias envolvendo atomistas e anti-atomistas relativas à aceitação do atomismo no século XIX.

Avaliando os resultados obtidos, conclui-se que o referencial histórico-epistemológico contribuiu para que os estudantes de Química envolvidos neste trabalho adquirissem uma imagem de ciência mais contextualizada e melhor formação inicial. A disciplina História da Química foi um espaço importante para que os alunos conhecessem melhor a natureza da ciência e aprendessem de forma significativa conceitos químicos. Ao final do trabalho, identificaram-se concepções menos simplistas e mais contextualizadas sobre a natureza da ciência e foram percebidos indícios de melhor compreensão de conceitos, como a quantidade de matéria e mol. Este artigo apresenta alguns resultados da primeira parte da investigação didática que integra a pesquisa da tese de doutorado da primeira autora ${ }^{3}$.

\section{História e Filosofia na educação científica}

A importância da História e Filosofia da Ciência para a educação científica tem sido amplamente reconhecida na literatura nas últimas décadas (PAIXÃO e CACHAPUZ, 2003; FREIRE JÚNIOR, 2002; LEITE, 2002; WANG e MARSH, 2002; NIAZ, 2001; SOLBES e TRAVERS, 1996; WORTMANN, 1996; MATTHEWS, 1994, 1990; GAGLIARD, 1988). Como conseqüência, vêm acontecendo ações oficiais e não oficiais no sentido de buscar inserir a História da Ciência nos currículos que têm emergido de reestruturações curriculares mais recentes. No Brasil, de alguma forma esta tendência aparece explicitada em documentos oficiais, como os Parâmetros Curriculares Nacionais para o Ensino Médio (PCNs) e as Novas Diretrizes Curriculares para os cursos de graduação.

\footnotetext{
${ }^{3}$ Um agradecimento especial ao professor Olival Freire Júnior, pelos comentários e sugestões sobre o artigo e pela orientação da tese (OKI, 2006).
} 
A inclusão da História da Ciência no ensino tem razões que se fundamentam na Filosofia e Epistemologia e a própria concepção de ciência adotada interfere na seleção e abordagem dos conteúdos. Considera-se que a incorporação de um maior conteúdo de História, Filosofia e Sociologia da Ciência nos currículos pode contribuir para a humanização do ensino científico, facilitando a mudança de concepções simplistas sobre a ciência para posições mais relativistas e contextualizadas sobre esse tipo de conhecimento (LUFFIEGO et al., 1994; HODSON, 1985).

Neste sentido, alguns projetos têm sido formulados em diferentes países, como o "Projeto 2061" da American Association for the Advancement of Science (AAAS), que originou, nos Estados Unidos, o livro Ciências para Todos (RUTHERFORD e AHLGREN, 1995). Nesse documento, retoma-se uma abordagem humanística para a educação em ciência, com prazo suficientemente amplo para que as mudanças aconteçam e possam ser viáveis. A História da Ciência é considerada conhecimento indispensável para a humanização da ciência e para o enriquecimento cultural, passando a assumir o elo capaz de conectar ciência e sociedade. Uma das importantes recomendações desse projeto consiste em ensinar menos para ensinar melhor. É deixada, aos curriculistas, a importante tarefa de promover reestruturações visando muito mais eliminar do que acrescentar conteúdos de ensino.

Não é necessário exigir das escolas que ensinem conteúdos cada vez mais alargados, mas sim que ensinem menos para ensinarem melhor. Concentrando-se em menos temas, os professores podem introduzir as idéias gradualmente, numa variedade de contextos, aprofundando-as e alargando-as à medida que os estudantes amadurecem. Os estudantes acabarão por adquirir conhecimentos mais ricos e uma compreensão mais profunda do que poderiam esperar adquirir a partir de uma exposição superficial de mais assuntos do que aqueles que seriam capazes de assimilar. O problema, para quem escreve os currículos, é, portanto, muito menos o que acrescentar do que o que eliminar. (RUTHERFORD e AHLGREN, 1995, p. 21, grifo nosso)

Ainda que a valorização desses campos na formação profissional tenha crescido, a inclusão desses temas nos currículos ainda segue um modelo tradicional, no qual, geralmente, disciplinas específicas abordam os conteúdos e a articulação com a didática é extremamente frágil. Tradicionalmente, o ensino da História das Ciências por disciplinas específicas não busca fazer uma ampla articulação com conteúdos da Filosofia da Ciência.

Um importante pesquisador que tem defendido a relevância da História e da Filosofia no ensino das ciências é Michael Matthews. Em artigos e livros escritos sobre esse assunto, ele defende a importância desses conteúdos no ensino sobre as ciências, tão importante quanto o ensino de ciências. Para Matthews (1994), ensinar sobre as ciências inclui tanto a discussão da dinâmica da atividade científica e de sua complexidade manifestada no processo de geração de produtos da ciência (hipóteses, leis, teorias, conceitos etc.) quanto a validação e divulgação do conhecimento científico, envolvendo alguma compreensão da dinâmica inerente a sua legitimação. 
A educação científica tradicional tem recebido muitas críticas e novas abordagens didáticas têm sido propostas, a exemplo da abordagem contextual ou liberal. Esses termos são usados por Matthews (1994) para se referir a uma educação científica informada pela História e Filosofia da Ciência. Embora a utilização deste tipo de abordagem tenha acontecido desde as primeiras décadas do século XX, somente ao final da década de 1940 as experiências realizadas tiveram maior repercussão. Naquele período, o químico e educador americano James Connant introduziu, em seus cursos de ciências, o estudo de certos episódios da História da Ciência, conhecidos como: History of Science Cases. Ele considerava que estudar como a ciência se desenvolveu poderia ajudar na compreensão da sua natureza (WANG e MARSH, 2002).

Influenciada pelo trabalho realizado por Connant e seus materiais didáticos inovadores, a abordagem contextual ganhou importância nos Estados Unidos após a Segunda Guerra Mundial. Outro precursor deste tipo de abordagem foi Gerald Holton, que apresentou uma metodologia para o ensino de Física, a abordagem conectiva ${ }^{4}$, valorizando as relações entre conteúdos específicos da Física e diferentes campos, como Astronomia, Biologia, Química, Economia, Filosofia, Matemática, Engenharia, História, Literatura, Psicologia etc. (HOLTON, 1963).

Considera-se que a opção didática pela História da Ciência deve acontecer de forma articulada com a Filosofia da Ciência, a fim de ajudar na análise crítica do conhecimento científico produzido e na transposição didática dos conteúdos.

\section{O ensino de História da Química e a compreensão da natureza da ciência}

A ausência de consenso no âmbito da Filosofia e Sociologia da Ciência em relação à imagem mais adequada de ciência e sua construção não causa surpresa, considerando-se o caráter complexo e dinâmico que caracteriza a atividade científica (ACEVEDO et al., 2005). O reconhecimento deste fato, no entanto, não impede a aceitação de alguma concordância sobre certos aspectos da natureza da ciência que podem ser norteadores das discussões na educação em ciências e das pesquisas realizadas sobre o tema (GIL-PÉREZ et al., 2001; HARRES, 1999; McCOMAS, ALMAZROA, CLOUGH, 1998; LEDERMAN, 1992).

Existem dois tipos de abordagem para introduzir conteúdos sobre a natureza da ciência no processo de ensino/aprendizagem: a implícita e a explícita. No primeiro, assume-se que na dinâmica adotada mensagens implícitas são comunicadas e que a construção do conhecimento acontece como conseqüência do engajamento no processo pedagógico. Os trabalhos devem possibilitar a inserção do aluno em atividades investigativas, incluindo instruções sobre a prática científica. $\mathrm{Na}$ abordagem explícita, os objetivos e materiais instrucionais são direcionados para aumentar a compreensão da natureza da ciência, de forma a incluir a discussão dos conteúdos epistemológicos. As atividades planejadas incluem investigações e exemplos

${ }^{4} \mathrm{O}$ termo abordagem conectiva é análogo ao termo abordagem contextual ou liberal utilizado por Matthews (1994). 
históricos que possibilitam discussões, reflexões guiadas e questionamentos específicos sobre o assunto (ABD-EL-KHALICK e LEDERMAN, 2000).

Apesar de algumas divergências detectadas nos resultados das pesquisas envolvendo concepções sobre a natureza da ciência, um aspecto consensual é o reconhecimento da importância da História e Filosofia da Ciência no aprimoramento das concepções de alunos e professores, em especial mediante estratégias de formação que fazem uso de abordagens explícitas, as quais têm se mostrado mais eficientes. Entretanto, necessita-se de maior número de investigações empíricas para que seja avaliada a influência deste tipo de abordagem e sua maior ou menor eficácia na formação inicial.

\section{A investigação didática na disciplina História da Química}

A investigação relatada neste artigo aconteceu numa disciplina específica para o ensino de História da Química, que faz parte do currículo do Curso de Química da Universidade Federal da Bahia, sendo obrigatória para os alunos de Licenciatura em Química daquela universidade. A disciplina foi incluída no currículo do curso desde a década de 1980 e tem sido ministrada desde o início da década de 1990 mediante pareceria entre dois professores.

A investigação didática foi realizada durante dois semestres consecutivos e os instrumentos de coleta de dados foram aplicados em sala de aula, durante os períodos letivos da disciplina. O primeiro semestre funcionou como um estudo piloto, que possibilitou o aprimoramento e validação de instrumentos utilizados para o levantamento de dados.

O desenvolvimento da pesquisa, que teve abordagem qualitativa e caráter exploratório, envolveu dois professores em sala, um deles a pesquisadora. Os sujeitos foram os alunos da disciplina. Todos os alunos matriculados participaram da investigação, uma vez que o módulo da disciplina é pequeno, o que justificou a não utilização de técnicas de amostragem para o levantamento de dados (BOGDAN e BIKLEN, 1994)

Para incluir conteúdos sobre a natureza da ciência na disciplina utilizou-se uma abordagem de ensino direcionada e contextualizada, priorizando o referencial da História e Filosofia da Ciência no processo. Levou-se em conta a constatação de Matthews (1994) de que a epistemologia dos alunos é comumente constituída informalmente, uma vez que não encontra respaldo adequado nos cursos de formação inicial.

Para investigar as questões propostas a disciplina foi reestruturada, com objetivo de incorporar diversas dimensões epistemológicas como parte de seu conteúdo. Articularam-se os conteúdos históricos tradicionalmente trabalhados numa perspectiva cronológica, com conteúdos de natureza epistemológica, abordados nos diversos contextos históricos. Todo o planejamento das aulas foi realizado para que diversas dimensões epistemológicas pudessem ser adequadamente contempladas.

A metodologia didática aconteceu em três momentos: inicialmente (momento antes) realizou-se o levantamento das concepções prévias relacionadas a conteúdos da Filosofia da Ciência que seriam priorizados na aula subseqüente, usando pequenos questionários contendo questões problematizadoras (Quadro 1). 
Oki, M. C. M.; Moradillo, E. F.

\begin{tabular}{|c|c|c|c|}
\hline $\begin{array}{c}\text { Dimensões da } \\
\text { análise/contextos } \\
\text { históricos }\end{array}$ & Objetivos & $\begin{array}{c}\text { Questões } \\
\text { problematizadoras }\end{array}$ & $\begin{array}{l}\text { Principais } \\
\text { referências }\end{array}$ \\
\hline $\begin{array}{l}\text { Origem do } \\
\text { conhecimento científico } \\
\text { Contexto histórico: } \\
\text { Os primórdios da } \\
\text { química/ o período das } \\
\text { artes práticas }\end{array}$ & $\begin{array}{l}\text { - Discutir sobre as } \\
\text { diferenças entre os } \\
\text { vários tipos de } \\
\text { conhecimento } \\
\text { - Compreender a } \\
\text { diferença entre } \\
\text { conhecimento científico } \\
\text { e saberes técnicos }\end{array}$ & $\begin{array}{l}\text { - Como os conhecimentos } \\
\text { científicos têm origem? } \\
\text { - Como você imagina que } \\
\text { aconteceu a produção } \\
\text { dos primeiros } \\
\text { conhecimentos que } \\
\text { hoje são chamados } \\
\text { de químicos? }\end{array}$ & $\begin{array}{l}\text { GRANGER, G. G. A } \\
\text { Ciência e as ciências. } \\
\text { São Paulo: Editora da } \\
\text { UNESP, 1994. p. } 24-36 .\end{array}$ \\
\hline $\begin{array}{l}\text { Concepção de ciência } \\
\text { Contexto histórico: } \\
\text { A filosofia grega }\end{array}$ & $\begin{array}{l}\text { - Discutir o conceito } \\
\text { de ciência } \\
\text { - Identificar as } \\
\text { características da } \\
\text { Ciência Química }\end{array}$ & $\begin{array}{l}\text { - Qual a sua concepção } \\
\text { de Ciência? } \\
\text { - Por que a Química é } \\
\text { uma ciência? }\end{array}$ & $\begin{array}{l}\text { ANDERY, M. A. et al. } \\
\text { Para compreender a } \\
\text { ciência. São Paulo: } \\
\text { EDUC, 1988. p.11-18. } \\
\text { CHALMERS, A. F. O que } \\
\text { é ciência afinal? São } \\
\text { Paulo: Brasiliense, } 1993 . \\
\text { p.17-22. }\end{array}$ \\
\hline $\begin{array}{l}\text { Demarcação entre } \\
\text { ciência e não ciência } \\
\text { Contexto histórico: } \\
\text { a Alquimia }\end{array}$ & $\begin{array}{l}\text { - Discutir sobre } \\
\text { critérios de } \\
\text { demarcação }\end{array}$ & $\begin{array}{l}\text { - A alquimia } \\
\text { se constituía numa } \\
\text { ciência? Explique. }\end{array}$ & $\begin{array}{l}\text { DUTRA, L. H. A. } \\
\text { Introdução a teoria da } \\
\text { ciência. Florianópolis: } \\
\text { Editora da UFSC, } 1998 . \\
\text { p. } 11-26 . \\
\text { ALFONSO-GOLDFARB, } \\
\text { A. M. Da alquimia à } \\
\text { química. São Paulo: } \\
\text { Nova Stella/Edusp, } 1987 . \\
\text { p. } 231-264 .\end{array}$ \\
\hline $\begin{array}{l}\text { A metodologia } \\
\text { científica } \\
\text { Contexto histórico: } \\
\text { A transição da alquimia } \\
\text { para a química }\end{array}$ & $\begin{array}{l}\text { - Identificar as principais } \\
\text { características do } \\
\text { conhecimento científico } \\
\text { - Reconhecer as } \\
\text { diferentes formas de } \\
\text { produção do } \\
\text { conhecimento científico }\end{array}$ & $\begin{array}{l}\text { - Existe um método } \\
\text { científico? } \\
\text { - Se a sua resposta } \\
\text { anterior for afirmativa, } \\
\text { quais as etapas } \\
\text { envolvidas neste método? }\end{array}$ & $\begin{array}{l}\text { MOREIRA, M. A. Sobre o } \\
\text { ensino do método } \\
\text { científico. Caderno } \\
\text { Catarinense de } \\
\text { Ensino de Física, v. } \\
\text { 10, n. 1, p.108-117, } \\
1993 .\end{array}$ \\
\hline $\begin{array}{l}\text { A experimentação na } \\
\text { produção do } \\
\text { conhecimento científico } \\
\text { Contexto histórico: } \\
\text { A revolução científica } \\
\text { nos séculos XVI e XVII }\end{array}$ & $\begin{array}{l}\text { - Discutir o conceito de } \\
\text { experimentação na } \\
\text { ciência }\end{array}$ & $\begin{array}{l}\text { - Na sua opinião o que é } \\
\text { um experimento? } \\
\text { O desenvolvimento do } \\
\text { conhecimento científico } \\
\text { sempre requer } \\
\text { experimentos? Justifique. }\end{array}$ & $\begin{array}{l}\text { ANDERY, M. A. et al. } \\
\text { Para compreender a } \\
\text { ciência. São Paulo: } \\
\text { EDUC, 1988. p.190-197. }\end{array}$ \\
\hline $\begin{array}{l}\text { Relações entre } \\
\text { hipótese, lei, teoria e } \\
\text { observação } \\
\text { Contextos históricos: } \\
\text {. A teoria do flogisto; } \\
\text {. As leis de combinação } \\
\text { química e a hipótese } \\
\text { atômica no século XIX }\end{array}$ & $\begin{array}{l}\text { - Discutir o significado } \\
\text { dos termos: hipótese, lei, } \\
\text { teoria } \\
\text { - Discutir a relação entre } \\
\text { a observação e a teoria }\end{array}$ & $\begin{array}{l}\text { - Na perspectiva da } \\
\text { ciência, como você } \\
\text { define: hipótese; lei e } \\
\text { teoria } \\
\text { - Qual a diferença entre } \\
\text { teoria e lei (científicas)? }\end{array}$ & $\begin{array}{l}\text { KNELLER, G. F. A } \\
\text { ciência como } \\
\text { atividade humana. } \\
\text { São Paulo: Zahar/Edusp, } \\
\text { 1980. p.122-154. } \\
\text { OKI, M. C. M. } \\
\text { Controvérsias sobre } \\
\text { o atomismo no } \\
\text { século XIX: parte II. } \\
\text { Salvador, } 2004 \text {. }\end{array}$ \\
\hline
\end{tabular}


O ensino de história da Química: ...

\begin{tabular}{|c|c|c|c|}
\hline $\begin{array}{c}\text { Dimensões da } \\
\text { análise/contextos } \\
\text { históricos }\end{array}$ & Objetivos & $\begin{array}{c}\text { Questões } \\
\text { problematizadoras }\end{array}$ & $\begin{array}{l}\text { Principais } \\
\text { referências }\end{array}$ \\
\hline $\begin{array}{l}\text { Imagem do cientista } \\
\text { Contexto histórico: } \\
\text { A revolução científica } \\
\text { de Lavoisier }\end{array}$ & $\begin{array}{l}\text { - Discutir o papel de } \\
\text { Lavoisier na constituição } \\
\text { da Química Moderna } \\
\text { - Discutir sobre a } \\
\text { imagem do cientista }\end{array}$ & $\begin{array}{l}\text { - Na sua opinião, qual a } \\
\text { principal contribuição de } \\
\text { Lavoisier para a Química } \\
\text { Moderna? }\end{array}$ & $\begin{array}{l}\text { FILGUEIRAS, C.A. L. } \\
\text { A revolução química } \\
\text { de Lavoisier: uma } \\
\text { verdadeira revolução? } \\
\text { Química Nova, v. 18, } \\
\text { n. 2, p. 219-224, 1995. } \\
\text { OKI, M. C. M. Paradigmas } \\
\text { crises e revoluções: a } \\
\text { História da Química na } \\
\text { perspectiva kuhniana } \\
\text { Química Nova na } \\
\text { Escola, n. 20, p. 32-37, } \\
\text { 2004. }\end{array}$ \\
\hline $\begin{array}{l}\text { O contexto da } \\
\text { descoberta científica } \\
\text { Contexto histórico: } \\
\text { A origem do conceito } \\
\text { de átomo e do } \\
\text { atomismo daltoniano. }\end{array}$ & $\begin{array}{l}\text { - Discutir sobre a origem } \\
\text { do conceito de átomo }\end{array}$ & $\begin{array}{l}\text { - O que você sabe } \\
\text { sobre a origem } \\
\text { histórica do conceito } \\
\text { de átomo? }\end{array}$ & $\begin{array}{l}\text { OKI, M. C. M. } \\
\text { Controvérsias sobre } \\
\text { o atomismo no } \\
\text { século XIX: parte II. } \\
\text { Salvador, } 2004 .\end{array}$ \\
\hline $\begin{array}{l}\text { Os modelos na ciência } \\
\text { Contexto histórico: } \\
\text { Controvérsias sobre o } \\
\text { atomismo no século XIX }\end{array}$ & $\begin{array}{l}\text { - Discutir sobre a } \\
\text { dificuldade de aceitação } \\
\text { da realidade atômica no } \\
\text { século XIX } \\
\text { - Entender a relação } \\
\text { entre modelo e realidade }\end{array}$ & $\begin{array}{l}\text { - Como você define } \\
\text { um modelo científico? } \\
\text { - Por que os modelos } \\
\text { são usados na ciência? }\end{array}$ & $\begin{array}{l}\text { OKI, M. C. M. } \\
\text { Controvérsias sobre } \\
\text { o atomismo no } \\
\text { século XIX: parte II. } \\
\text { Salvador, } 2004 \text {. } \\
\text { DUTRA, L. H. A. } \\
\text { Introdução a teoria } \\
\text { da ciência. } \\
\text { Florianópolis: Editora da } \\
\text { UFSC, 1998. p.15-17. }\end{array}$ \\
\hline
\end{tabular}

Quadro 1. Resumo do planejamento semestral de aulas.

No momento inicial os alunos tomavam conhecimento do planejamento feito para o próximo encontro, sendo informados sobre as leituras que forneceriam subsídios às discussões. Os textos eram disponibilizados para serem fotocopiados e lidos. $\mathrm{Na}$ aula seguinte, acontecia a discussão dos assuntos que faziam parte do planejamento, subsidiada pelas leituras indicadas. Tanto os alunos quanto os professores se colocavam sobre o assunto, priorizando os objetivos definidos para aquela aula. Posteriormente (momento depois), os alunos se reuniam em grupos e voltavam a discutir as questões respondidas na aula anterior (levantamento prévio). Após a discussão, cada aluno refletia sobre as questões e novamente as respondia. $\mathrm{O}$ principal objetivo era avaliar se as informações adquiridas por meio das leituras e discussões tinham possibilitado algum ganho no conhecimento epistemológico dos alunos.

A percepção de necessidade de aprofundamento das observações realizadas e o levantamento de concepções prévias foram possibilitados pela utilização de diversos instru- 
Oki, M. C. M.; Moradillo, E. F.

mentos de coleta de dados: questionários, gravações das discussões em grupos e entrevistas semi-estruturadas. O uso de questionários abertos contendo questões problematizadoras objetivou permitir aos estudantes revelarem e justificarem sua própria opinião sem ter que escolher entre visões já pré-estabelecidas que, eventualmente, poderiam não corresponder exatamente à deles.

O corpus de análise envolveu o conjunto de respostas aos questionários, as transcrições das entrevistas, os registros de observações e as anotações sobre as aulas, em especial as do segundo semestre escolhido para realização da pesquisa.

\section{Análise e discussão dos resultados}

A análise priorizou algumas categorias analíticas definidas previamente e subdivididas em diferentes dimensões (Quadros 2, 3 e 4). Embora tenha sido abordado maior número de aspectos da natureza da ciência durante as aulas, as prioridades e os recortes foram necessários para que a análise dos dados não se tornasse muito ampla. Na definição das categorias analíticas utilizou-se o modelo misto. Segundo Laville e Dionne (1999), neste modelo algumas categorias são selecionadas no início, baseadas no referencial teórico utilizado, mas o pesquisador pode modificá-las em função do que a análise indicar. As categorias definidas a priori (categorias epistemológicas) nortearam, também, as dimensões de análise, de natureza epistemológica, que foram escolhidas para orientar as entrevistas semi-estruturadas.

A metodologia de análise dos dados envolveu, também, a identificação de categorias emergentes obtidas das respostas dos alunos, antes e após a discussão, para posterior comparação (MORAES, 1999; TRIVIÑOS, 1987). O número de alunos presentes na aula em que foram feitos os levantamentos prévios nem sempre foi o mesmo do segundo momento, variando conforme a freqüência às aulas. Todos os trechos de falas dos alunos citados foram obtidos de gravações efetuadas simultaneamente nos três grupos de discussão durante os dois semestres letivos.

A primeira categoria epistemológica definida foi: ciência e conhecimento científico; subdividida em três dimensões de análise e consideradas em três contextos históricos, conforme ilustra o Quadro 2:

\begin{tabular}{|c|c|c|}
\hline Primeira categoria epistemológica & Dimensão da análise & Contextos históricos \\
\hline Ciência e conhecimento científico & Origem do conhecimento científico & O período das artes práticas \\
\hline Ciência e conhecimento científico & Concepção de ciência & $\begin{array}{c}\text { A Filosofia e Ciência Grega e } \\
\text { o surgimento do conceito de } \\
\text { átomo }\end{array}$ \\
\hline Ciência e conhecimento científico & $\begin{array}{c}\text { Critérios de demarcação } \\
\text { Ciência x Pseudo-ciência }\end{array}$ & A alquimia \\
\hline
\end{tabular}

Quadro 2. Primeira categoria epistemológica. 
Para exemplificar o resultado obtido toma-se a terceira dimensão de análise definida para a primeira categoria epistemológica: a demarcação entre ciência e pseudo-ciência, discutida no contexto da alquimia. Entre os alunos que se matriculavam em História da Química predominava uma visão distorcida da Alquimia, como um tipo de prática sem significado científico, repleta de charlatanismo e magia ou pseudo-ciência.

Tabela 1. Alquimia x ciência.

\begin{tabular}{|c|c|c|}
\hline Sim/Não & Categoria & $\begin{array}{l}n^{\circ} \text { de } \\
\text { alunos }\end{array}$ \\
\hline Não & C1- Seria uma corrente filosófica oculta & 01 \\
\hline Não & $\begin{array}{l}\text { C2- A alquimia não explicava o porque dos fatos, dos fenômenos e nem cuidava da } \\
\text { propagação }\end{array}$ & 02 \\
\hline Não & $\begin{array}{l}\text { C3- Os alquimistas descobriam as coisas de uma forma empírica, sem provar a } \\
\text { descoberta }\end{array}$ & 01 \\
\hline Não & C4- A alquimia não tinha conhecimentos prévios, eles foram surgindo ao acaso & 01 \\
\hline Não & C5- Era baseada apenas na observação & 01 \\
\hline Não & C6- Não apresentava um embasamento metodológico, científico e didático & 01 \\
\hline Não & C7- Quem sabe era uma pré-ciência & 01 \\
\hline $\operatorname{Sim}$ & $\begin{array}{l}\text { C8- Estudava os problemas relacionados com o conhecimento no sentido de } \\
\text { obter materiais existentes }\end{array}$ & 01 \\
\hline $\operatorname{Sim}$ & c9- Produziu conhecimentos & 01 \\
\hline Sim & C10- Porém não se reconhecia a alquimia como ciência & 01 \\
\hline
\end{tabular}

A Tabela 1 apresenta as respostas dos alunos à pergunta problematizadora: a alquimia se constituía numa ciência? Explique. Utilizou-se a legenda $\mathrm{CN}(\mathrm{C}=$ categoria e $\mathrm{N}=$ número do aluno) para identificar as diferentes categorias emergentes obtidas das respostas no momento inicial. Nas respostas da Tabela 1 identificam-se alguns critérios que os alunos utilizavam para distinguir o que imaginavam ser científico e que caracterizava a ciência em contraposição à alquimia como:

- explica o porquê dos fatos e fenômenos e divulga as explicações (C2);

- descobre coisas não só de forma empírica e 'prova' as descobertas (C3);

- não se baseia apenas na observação (C5);

- possui conhecimentos prévios (C4);

- apresenta embasamento metodológico (C6);

- estuda os problemas relacionados ao conhecimento (C8). 
Estas respostas revelam, em alguma medida, uma visão de Ciência como meio de descobrir o que existe no mundo (desvelamento da natureza) ou de explicar os fenômenos, na busca de provas ou 'verdades', demonstrando a presença de concepções realistas ingênuas. Verifica-se que nas visões distorcidas sobre o que foi a alquimia encontram-se implícitas concepções simplistas sobre os critérios de demarcação da ciência. Não pareceu existir o reconhecimento da produção do conhecimento científico como construção humana contextualizada.

Vale lembrar a complexidade inerente ao conceito de ciência, que poderia demandar uma discussão tão fecunda capaz de ocupar todo um livro. Alan Chalmers se propôs ao desafio de realizar esta tarefa, tendo escrito seu famoso $O$ que é ciência afinal? Após uma longa discussão, que envolveu 14 capítulos e 216 páginas, Chalmers (1995) assim se coloca com relação à sua pergunta inicial:

A estrutura de grande parte dos argumentos desse livro foi de desenvolver relatos do tipo de coisa que é a Física e testá-los no confronto com a Física real. Diante dessa consideração sugiro que a pergunta que constitui o título desse livro é enganosa e arrogante. Ela supõe que exista uma única categoria "ciência" e implica que várias áreas do conhecimento, a Física, a Biologia, a História, a Sociologia e assim por diante se encaixem ou não nesta categoria. (CHALMERS, 1995, p. 211)

Chalmers (1995) considera que cada área do conhecimento pode ser julgada por aquilo que é, não havendo necessidade de uma categoria geral "ciência", que possa servir de modelo para que outras áreas do conhecimento possam ser avaliadas à luz deste modelo e proclamadas - ou não - como ciência. Ainda em relação a este assunto, ele assim se posiciona: "Cada área do conhecimento deve ser julgada pelos próprios méritos, pela investigação de seus objetivos, e, em que extensão é capaz de alcançá-los. Mas ainda, os próprios julgamentos relativos aos objetivos serão relativos à situação social" (p. 212).

Este autor, entretanto, procura evitar que suas idéias sejam enquadradas em posições relativistas extremas, buscando manter uma tendência "objetivista" em seus pontos de vista, mesmo discordando de um conceito universal e atemporal de ciência ou de método científico.

As idéias de filósofos como Kuhn (1996) e Feyerabend (1989) contribuíram para a flexibilização dos critérios de cientificidade, em especial na delimitação entre ciência e não ciência. A possibilidade de usar a cientificidade de forma mais ampla, com aceitação de uma pluralidade de métodos de pesquisa, permitiu o reconhecimento do status científico de outras ciências - e não apenas das naturais, além de um "alargamento" em sua concepção.

$\mathrm{Na}$ visão tradicional, a atividade científica é vista como independente das relações sociais e o conhecimento científico é considerado seguro, porque baseado em evidências observacional e experimental. Esta imagem tem forte influência de correntes epistemológicas, como o positivismo e o empirismo lógico, e de seus reflexos no ensino de ciência e nas imagens de ciência dos alunos. Nesta perspectiva, os enunciados da ciência se fundamentariam, em última instância, nos fatos, nos dados da experiência. A ciência seria, portanto, portadora de verdades inquestionáveis (GIL-PÉREZ et al., 2001; SALMON, 2000).

A confiança no método que a ciência utiliza foi um importante critério de demarca- 
ção considerado pelos alunos. No entanto, quando mapearam-se as concepções sobre o tema no segundo momento, percebeu-se a relativização desse critério por meio da discussão que aconteceu em um dos grupos sobre a cientificidade da alquimia. Os alunos foram identificados pela sigla "AN", na qual: $\mathbf{A}=$ aluno e $\mathbf{N}=$ número de identificação de cada aluno.

"Eu acho que sim, a ciência ela tem um objetivo e a alquimia tinha objetivos e trabalhou para obter e atingir estes objetivos e, além disso [...]" (A6)

"Além disso, ela tinha métodos". (A1)

"Tinha métodos e tinha conhecimentos para obter determinados resultados". (A6)

"Eu acho que ela era ciência porque tinha estes três pontos: objetivos, métodos e conbecimento [....]. Antes, quando eu não conbecia nada sobre alquimia, porque eu a conhecia como uma forma de bruxaria, porque eu não sabia de nada; mas agora depois das leituras e dessa aula ficamos sabendo que eles (os alquimistas) descobriram alguns elementos, as aparelhagens que eles utilizavam, algumas técnicas como a destilação e o banho maria e os fenômenos que eles observavam, imaginando que acontecia a transmutação dos metais menos nobres para ouro ou prata [...]”. (A1)

"Eles não tinham ainda o conhecimento da estrutura e das reações quimicas e analisavam da maneira que eles achavam que era correta na época". (A5)

"Na realidade estava bavendo uma transformação, mas não de um metal menos nobre para outro mais nobre”. (A1)

"No contexto do conbecimento que eles tinham naquela época, considero que era uma ciência [...]". (A5)

Nesse momento, identificou-se, em todas as equipes, uma visão contextualizada da Alquimia. O objetivo era que eles manifestassem uma visão histórica da Alquimia, a partir de uma releitura crítica do período medieval, contextualizando os alquimistas e a Alquimia naquele período e reconhecendo sua contribuição para a constituição da Química Moderna. Os alunos passaram a perceber a necessidade de flexibilização nos critérios utilizados para demarcação da ciência.

No trecho a seguir, a historiadora da Química Ana Maria Goldfarb, uma das referências utilizadas para subsidiar as discussões em sala, procura dar visibilidade à importância da Alquimia para a constituição da Química Moderna.

Os estudiosos de nosso século, dedicados à história da ciência e, particularmente, da alquimia, partem, na maioria das vezes, do pressuposto de que não foi a ignorância, irracionalidade ou obscurantismo das culturas que nos precederam o que preservou a alquimia. Mas, ao contrário, foi exatamente nos períodos em que mais se valorizou o 
Oki, M. C. M.; Moradillo, E. F.

conhecimento da natureza onde a alquimia floresceu. (GOLDFARB, 1987, p. 265)

A ciência é uma das formas de conhecimento produzidas pelo homem no decorrer da sua história e seu caráter histórico se manifesta nas representações que o homem faz, inclusive para o próprio conhecimento.

A imagem de ciência que tem na experimentação a essência de sua atividade tem sido considerada uma visão deformada da atividade científica. Entretanto, encontra-se amplamente difundida no ensino tradicional de ciências. A crença na unicidade do método científico é uma deformação presente tanto entre professores quanto entre alunos dos cursos das ciências, uma vez que o método científico costuma ser visto como uma maneira segura de chegar ao conhecimento científico (GIL-PÉREZ et al., 2001; MOREIRA, 1993). Considerando tais questões, a segunda categoria epistemológica definida foi a dinâmica da ciência e seus produtos. Esta categoria foi subdividida em quatro dimensões consideradas em diferentes contextos históricos (Quadro 3):

\begin{tabular}{|c|c|c|}
\hline $\begin{array}{c}\text { Segunda categoria } \\
\text { epistemológica }\end{array}$ & Dimensão da análise & Contextos históricos \\
\hline $\begin{array}{c}\text { A dinâmica da ciência } \\
\text { e os seus produtos }\end{array}$ & As metodologias científicas & $\begin{array}{c}\text { A transição da alquimia } \\
\text { para a química moderna }\end{array}$ \\
\hline $\begin{array}{c}\text { A dinâmica da ciência } \\
\text { e os seus produtos }\end{array}$ & $\begin{array}{c}\text { A experimentação na produção } \\
\text { do conhecimento científico }\end{array}$ & $\begin{array}{c}\text { As revoluções científicas } \\
\text { nos séculos XVI e XVII }\end{array}$ \\
\hline $\begin{array}{c}\text { A dinâmica da ciência } \\
\text { e os seus produtos }\end{array}$ & $\begin{array}{c}\text { A relação entre hipóteses, } \\
\text { leis e teorias }\end{array}$ & $\begin{array}{c}\text { A teoria do flogisto ou flogístico; } \\
\text { As leis de combinação química e a } \\
\text { hipótese atômica no século XIX }\end{array}$ \\
\hline $\begin{array}{c}\text { A dinâmica da ciência } \\
\text { e os seus produtos }\end{array}$ & O contexto da descoberta científica & $\begin{array}{c}\text { A origem do conceito de átomo e } \\
\text { do atomismo daltoniano }\end{array}$ \\
\hline
\end{tabular}

Quadro 3. Segunda categoria epistemológica.

Para averiguar o pensamento dos alunos sobre esse assunto, usou-se a questão problematizadora apresentada na Tabela 2, contendo categorias construídas a partir de suas respostas (Legenda: $\mathbf{C A}=$ Categoria Antes; $\mathbf{C D}=$ Categoria Depois).

Inicialmente, apenas um aluno, entre os dez presentes àquela aula, respondeu negativamente à questão (CA11). Ele justificou sua resposta informando que anteriormente havia feito uma leitura sobre o caráter histórico do método científico, o que o levou a assumir uma opinião diferente dos demais colegas. Na categoria antes (CA10) apareceu uma contradição: embora o aluno tenha respondido afirmativamente, sua justificativa admitia diferentes métodos, a depender da área. No primeiro momento, a maioria dos alunos (dez) achava que existia um único método científico, embora individualmente divergissem quanto às possíveis etapas desse método. O método científico costuma ser visto como uma maneira segura de se chegar ao conhecimento científico (MOREIRA, 1993; GIL-PÉREZ et al., 2001). 
A concepção de que existe um método científico (nove alunos) que começa na observação (cinco alunos) ou tem esta etapa como indispensável para a produção de conhecimento (sete alunos) ficou evidente na maior parte das respostas. A idéia predominante é que o fenômeno fala por si só, o mais importante é saber a melhor forma de olhar para chegar a seu desvelamento.

Tabela 2. O método científico e as etapas deste método.

Pergunta: Existe um método científico? Se a sua resposta à pergunta anterior for afirmativa, quais as etapas envolvidas neste método?

\begin{tabular}{|c|c|c|c|c|c|}
\hline $\begin{array}{l}\text { Momento } \\
\text { Antes }\end{array}$ & Justificativa/Etapas & $\begin{array}{l}\mathrm{n}^{\circ} \mathrm{de} \\
\text { alunos }\end{array}$ & $\begin{array}{l}\text { Momento } \\
\text { Depois }\end{array}$ & $\begin{array}{l}\text { Justificatival } \\
\text { Etapas }\end{array}$ & $\begin{array}{l}\mathrm{n}^{\circ} \text { de } \\
\text { alunos }\end{array}$ \\
\hline Existe & $\begin{array}{l}\text { CA1-Levantamento de hipóteses, } \\
\text { experimentação, verificação das } \\
\text { hipóteses; conclusão }\end{array}$ & 01 & & & \\
\hline Existe & $\begin{array}{l}\text { CA2- Programação, sistematização e } \\
\text { controle }\end{array}$ & 01 & & & \\
\hline Existe & $\begin{array}{l}\text { CA3- Parte-se da observação, depois } \\
\text { a experimentação }\end{array}$ & 01 & & & \\
\hline Existe & $\begin{array}{l}\text { CA4- Observação das transformações; } \\
\text { investigação das causas; divulgação do } \\
\text { conhecimento adquirido }\end{array}$ & 01 & & & \\
\hline Existe & $\begin{array}{l}\text { CA5- Observação ou idéia; pesquisa; } \\
\text { seleção de material; experimento e/ou } \\
\text { observação; levantamento de hipóteses; } \\
\text { experimentos; conclusões; teoria; lei }\end{array}$ & 01 & & & \\
\hline Existe & CA6- Observação, análise e reprodução & 01 & & & \\
\hline Existe & $\begin{array}{l}\text { CA7- Pesquisa; observação; } \\
\text { experimentação }\end{array}$ & 01 & & & \\
\hline Existe & $\begin{array}{l}\text { CA8- Teorização, experimento; } \\
\text { formulação de hipóteses e observações }\end{array}$ & 01 & & & \\
\hline Existe & $\begin{array}{l}\text { CA9- Observação; experimentação; } \\
\text { proposição de hipóteses e conclusão }\end{array}$ & 01 & & & \\
\hline Sim & $\begin{array}{l}\text { CA10- Embora cada área tenha um } \\
\text { método }\end{array}$ & 01 & & & \\
\hline \multirow[t]{2}{*}{ Não } & CA11- Existem vários métodos & 01 & & & \\
\hline & & & Não & $\begin{array}{l}\text { CD12- Vários métodos } \\
\text { são possíveis nas } \\
\text { diferentes áreas e } \\
\text { períodos históricos }\end{array}$ & 09 \\
\hline
\end{tabular}


A experimentação também foi uma etapa bastante citada, refletindo a força da epistemologia empirista no ensino de ciências (CA1, CA3, CA5, CA7, CA8, CA9). Apenas um aluno considerava que o método científico iniciava-se com a colocação de hipóteses (CA1), enquanto um outro achava que iniciava com a teorização (CA8). Os alunos não reconheciam a dependência que a observação tem da teoria, não se dando conta que o percebido não depende apenas da realidade externa, mas dos conhecimentos prévios e da bagagem teórica de cada um. A não separação entre pressupostos teóricos e observacionais foi defendida por vários filósofos da ciência pós-positivistas, como Popper (2001), Kuhn (1996), Hanson (1975) e Feyerabend (1989), entre outros.

Durante o curso foram utilizadas as idéias de Francis Bacon, que defendia a observação neutra como origem do conhecimento científico para discutir e questionar o caminho empirista-indutivista de chegar às teorias, indo do particular ao geral (BACON, 1984). Chamou-se a atenção sobre a influência dessas idéias e do positivismo comtiano no ensino de ciência, em relação à aceitação de um método científico estruturado rigidamente. Losee (1998) lembra que o empirismo e a indução predominaram até o início do século XX, tendo servido de base ao positivismo. A filosofia positivista defendia que a ciência devia se basear na observação direta dos fatos e não nas hipóteses.

No momento pós-discussão (Tabela 2), percebeu-se convergência nas respostas dos alunos e foi identificada uma única categoria depois $(\mathbf{C D})$, uma vez que todos os alunos presentes àquela aula (nove) passaram a reconhecer a existência de vários métodos científicos e o caráter histórico desses métodos (CD12).

No diálogo gravado após as leituras e discussões em sala foi possível detectar maior adequação nas concepções sobre o método científico dos alunos, em todos os grupos. Esta foi uma das dimensões em que aconteceu maior transformação em relação às idéias iniciais. $O$ diálogo a seguir, registrado em uma das equipes, exemplifica esta afirmação:

"O método científico, ele não é um único e eles (os métodos) se transformam, ao meu ver, no decorrer da história”. (A10)

"Eu sempre pensei que existia um método científico, depois que li o texto, eu não continuo pensando num método cientifico fixo, único, mas existem métodos, maneiras de se chegar aos resultados e não etapa por etapa”. (A7)

"Talvez, cada área da ciência tenha algumas determinações específicas, maneiras diferentes de pesquisar". (A13)

Um dos focos de investigação na Epistemologia da Química têm sido as representações feitas pelos cientistas dos vários aspectos do mundo para diferentes propósitos. O interesse nessa questão é uma conseqüência do largo uso de modelos e outros 'construtos' teóricos como instrumentos da educação científica. Grande parte da atividade do cientista consiste na construção de modelos que servem de representação dos fenômenos estudados e a integração desses modelos a teorias científicas possibilita a resolução de inúmeros problemas.

Existe o reconhecimento de que os estudantes de ciência possuem não somente teorias e conceitos distorcidos sobre alguma matéria específica estudada, como também concep- 
ções epistemológicas ingênuas e equivocadas, que precisam ser repensadas. Uma sugestão para enfrentar este problema seria incluir, no ensino "sobre" as ciências, a questão da natureza e o uso dos modelos científicos e didáticos. Alguns educadores atribuem a este tema uma importância tão grande que defendem um conceito de ciência como "processo de construção de modelos conceituais preditivos" (GILBERT, 1991, p. 74).

Considerando a relevância do papel da idealização e dos modelos no ensino de ciências e na epistemologia da Química, pela formulação de duas questões investigou-se o entendimento que os estudantes possuíam sobre o conceito de modelo e seu uso na ciência. A ciência e a representação da realidade foram tomadas como terceira categoria epistemológica, que incluiu duas dimensões de análise: a natureza dos modelos e seu uso na ciência. O contexto histórico discutido envolveu o atomismo no século XIX e as controvérsias envolvendo atomistas e anti-atomistas naquele período.

\begin{tabular}{|c|c|c|}
\hline $\begin{array}{c}\text { Terceira categoria } \\
\text { epistemológica }\end{array}$ & Dimensão da análise & Contextos históricos \\
\hline $\begin{array}{c}\text { A ciência e a representação } \\
\text { da realidade }\end{array}$ & A natureza dos modelos científicos & $\begin{array}{c}\text { Controvérsias sobre o atomismo } \\
\text { no século XIX }\end{array}$ \\
\hline $\begin{array}{c}\text { A ciência e a representação } \\
\text { da realidade }\end{array}$ & O uso dos modelos científicos & $\begin{array}{c}\text { Controvérsias sobre o atomismo } \\
\text { no século XIX }\end{array}$ \\
\hline
\end{tabular}

Quadro 4. Terceira categoria epistemológica.

A palavra modelo é amplamente utilizada, seja no cotidiano ou, mesmo, no âmbito das várias ciências e do ensino de ciências. Vários significados são atribuídos a ela, sendo o mais comum o de representação concreta de alguma coisa, justificando o fato de muitos estudantes considerarem que modelos são cópias da realidade.

No âmbito da ciência e da filosofia da ciência, não existe um significado único para a palavra modelo. A noção de modelo científico tem estado muito ligada à de teoria. No entanto, discussões mais recentes têm possibilitado o reconhecimento de suas especificidades, apontando para a necessidade de independência na formalização de ambos (GIERE, 2004).

Galagovsky e Adúriz-Bravo (2001) consideram que os modelos contêm articulações de um grande número de hipóteses de um altíssimo nível de abstração e com alto grau de formalização. Entretanto, na Química isto nem sempre é válido. Para os químicos, os modelos são representações não somente de objetos, mas de eventos, processos ou idéias. E estas representações podem acontecer de forma concreta, verbal, visual ou matemática (JUSTI e GILBERT, 2000).

Para levantar a concepção de modelo dos alunos entrevistados, foi solicitado que eles definissem um modelo científico. Os resultados estão expressos na Tabela 3. 
Oki, M. C. M.; Moradillo, E. F.

Tabela 3. A concepção de modelo científico.

Pergunta: Como você define um modelo científico?

$\begin{array}{lclc}\text { Categorias Antes } & \begin{array}{c}n^{\circ} \text { de } \\ \text { alunos }\end{array} & \text { Categorias Depois } & \begin{array}{r}n^{\circ} \text { de } \\ \text { alunos }\end{array}\end{array}$

CA1- É uma estrutura delimitada para se obter um perfil de um determinado objeto de estudo

CA2- É um desenho ou figura que representa a forma estrutural de algo que não pode ser observado a olho nu CA3- Algo que foi experimentado, deu certo e deve ser seguido

CA4- É um objeto para ser reproduzido como imitação

CA5- É algo estabelecido

criteriosamente, dentro de um

determinado contexto

CA6- É uma representação

CA7- Uma referência tomada como exemplo, ou padrão a ser seguido

CA8-Um instrumento usado para

representar algo ou um fato

CA9- É uma forma ou algo estruturado

com características próprias

CA10- É a representação de uma teoria
01

01

01

01

01

01 CD6- É a representação de algo (conceito, 01 teoria etc.).

02 CD7- É tudo que serve de parâmetro, algo padronizado que serve de referência

01

01

01 CD10- É uma forma de representação que possibilita a ilustração de certas teorias CD11- É uma forma de representação de determinados conceitos químicos CD12- É uma ferramenta que tenta representar uma realidade mais complexa que não pode ser diretamente visualizada

CD13- É uma forma material, concreta ou esquemática de demonstrar ou representar conceitos, teorias, etc.

CD14- È um tipo de representação simples e compreensível de um fenômeno, entidade etc., na tentativa de explicar o mesmo

CD15- É uma forma de representar algo complexo, que não pode ser visualizado, de forma simples e compreensível a todos

Inicialmente (momento antes), as respostas dos alunos foram muito dispersas, o que dificultou o agrupamento em categorias emergentes com características comuns. Dois alunos (CA6, CA10) definiram explicitamente modelo como representação, no entanto, um deles (CA10) foi mais específico, considerando-o "representação de uma teoria". Dois outros alunos consideravam o modelo como desenho ou instrumento que representa algo que não pode ser visto (CA2, CA8). A diversidade de entidades que podem ser modeladas não parecia ser reconhecida. Duas outras idéias foram identificadas: "a reprodução de algo como uma imitação" (CA4) ou "um padrão ou referência tomada para ser seguida" (CA7). 
No segundo momento, as respostas foram mais convergentes, predominando a idéia de "modelo como uma ferramenta ou forma de representar" ou como "um tipo de representação, seja de fenômenos, entidades, conceitos ou teorias" (CD10, CD11, CD12, CD14, CD15). Dois alunos consideraram "uma forma material (concreta) de representar conceitos ou teorias" (CD13). Dois alunos ainda explicitaram a idéia mais próxima do senso comum de modelo como "um padrão a ser tomado como referência" (CD7). Entretanto, um maior número de alunos passou a ter um conceito mais adequado de modelo científico, identificando-o como algum tipo de representação.

Debatendo sobre a possível realidade dos átomos no contexto das controvérsias sobre a aceitação do atomismo no século XIX, após o trabalho em sala de aula e as leituras dos textos registrou-se o seguinte trecho da discussão em um dos grupos que participaram do estudo:

"Eu defendo que o átomo existe, agora eu não posso afirmar que é da forma que en idealizei o meu modelo. Não posso, porque o modelo que eu tenho hoje, amanhã pode estar esgotado e a gente ainda está falando da mesma coisa. Olha o que o professor disse, os objetos são históricos, sujeitos e objetos são históricos, então eu acho que ele existe mas não é da maneira que eu [...]" (A4)

"Pode até ser [...], na realidade o que a gente não pode hoje é comprovar". (A8)

"Vocêpode sentir os seus efeitos [...] mas eu sei que ele existe [...]".(A4)

"Para nós, que trabalhamos com Química, se chegarmos aqui e disserem que o átomo não existe, cai o mundo da gente. Eu acredito piamente, agora a certeza absoluta a gente não tem, [...]". (A8)

Nessa discussão nota-se que os alunos expressaram a crença na realidade do átomo e ainda manifestavam uma visão realista ingênua, na qual acredita-se que a realidade existe independentemente da cognição e que as entidades teóricas da ciência são reais, devem ser descobertas e podem descrever o mundo como ele realmente é. Entretanto, os alunos reconheciam a necessidade de modelos para intermediar esta "suposta" entidade (o átomo), visualizada por meio de artifícios tecnológicos, e que tais modelos não são definitivos “[...] porque o modelo que eu tenho hoje, amanhã pode estar esgotado e a gente ainda está falando da mesma coisa” (A4).

O reconhecimento da importância do conceito de átomo na fundamentação teórica da Química atual também ficou evidente quando A8 afirmou: “[...] se chegarmos aqui e disserem que o átomo não existe, cai o mundo da gente".

A historicidade do conhecimento científico foi também expressa na afirmação do aluno A4: "Olha o que o professor disse, os objetos são históricos, sujeitos e objetos são históricos [...]". Mesmo remetendo à autoridade do professor, o aluno expressa sua percepção na mutabilidade do conhecimento científico.

Muitos campos conceituais da Química sofreram poucas transformações teóricas à luz da Teoria Quântica. Como conseqüência, grande parte dos conteúdos de Química do Ensino Médio e dos primeiros anos do Ensino Superior são embasados em modelos fortemente realistas, necessitando do uso de representações pictóricas para sua compreensão. Nessa abordagem, o átomo é compreendido como um sistema material, concreto e realista e este tipo de modelo é utilizado para a compreensão de alguns conteúdos químicos. 
Oki, M. C. M.; Moradillo, E. F.

Comentando sobre a influência do realismo na Química, Bachelard consegue expressar, em poucas palavras, sua forte presença na produção do conhecimento químico: "A experiência química aceita tão facilmente as proposições do realismo, que não se sente à necessidade de a traduzir numa outra filosofia" (BACHELARD, 1991, p. 50). Este filósofo propõe a distinção entre "real científico" e o "real dado", ou aparente, na qual o segundo é o próprio fenômeno ou evento, sendo relacionado ao senso comum. Contudo, a compreensão do conceito de real científico necessita da noção de "fenomenotécnica", porque é na relação sujeito-objeto mediada pela técnica que o real científico se concretiza. O real científico pressupõe um nível de realismo mais sofisticado que rompe com o empirismo que caracteriza as primeiras impressões.

É preciso haver outros conceitos além dos conceitos "visuais" para montar uma técnica de agir cientificamente-no-mundo e para promover à existência, mediante uma fenomenotécnica, fenômenos que não estão naturalmente-na-natureza. Só por uma desmaterialização da experiência comum se pode atingir um realismo da técnica científica. (BACHELARD, 1977, p. 137, grifo nosso)

Parece muito forte no ensino da Química a opção pelo realismo ingênuo em relação às representações químicas; o que aparentemente se mantém mesmo na universidade. Esta é uma situação que se contrapõe à produção do conhecimento químico ao longo da História, que precisou romper, muitas vezes, com o real dado e aparente. A frase de Bachelard expressa, de alguma forma, a influência do realismo na cultura química: "[...] a filosofia química mergulhou sem resistência no realismo. A Química tornou-se, assim, o domínio de eleição dos realistas, dos materialistas, dos antimetafísicos" (BACHELARD, 1991, p. 49).

$\mathrm{Na}$ Filosofia da Ciência contemporânea esta é uma discussão muito complexa e que envolve a própria noção de 'verdade'. Na perspectiva do realismo não representativo, por exemplo, o mundo físico existe, independente da nossa cognição. No entanto, esta tendência filosófica não considera que as teorias propostas descrevam entidades do mundo, não incorporando uma teoria da verdade da correspondência. Nesta perspectiva, não existe a possibilidade de acesso ao mundo independente das teorias (CHALMERS, 1995), perspectiva defendida por "novas" filosofias da ciência desenvolvidas no século XX.

\section{Considerações finais}

O trabalho realizado na disciplina História da Química, fundamentado numa abordagem explícita de conteúdos da Filosofia da Ciência, possibilitou algum ganho em relação aos conhecimentos epistemológicos detectados, inicialmente, entre os alunos pesquisados. Concepções mais elaboradas e menos ingênuas foram identificadas nos momentos posteriores ao trabalho didático realizado em cada aula, uma vez que detectou-se o aparecimento de novas categorias que refletiam posições mais racionalistas e contextualizadas sobre o conhecimento científico e a ciência. Entretanto, ao final do curso, alguns alunos ainda associavam o átomo a 
uma parte da realidade, fazendo afirmações carregadas de certo realismo ingênuo. Considerase que esta seja uma questão complexa que evidencia a grande penetração de realismo ingênuo no ensino de Química, em especial em relação às representações químicas.

A abordagem de controvérsias científicas na disciplina foi avaliada positivamente, considerando-se que ela possibilitou, em especial, o reconhecimento da ciência como uma atividade humana sujeita a erros e conflitos, além da percepção do caráter provisório do conhecimento científico e da complexidade envolvida no contexto da justificação de novas teorias científicas.

Os resultados obtidos nesta parte da investigação confirmaram a expectativa inicial de que mesmo numa disciplina específica de História da Química é possível introduzir conteúdos de Filosofia da Ciência, envolvendo os alunos em discussões sobre este assunto e possibilitando maior compreensão da natureza da ciência. A disciplina História da Química é um espaço privilegiado no currículo para discussões sobre a natureza da ciência com os alunos, durante a formação inicial. Reconhece-se, no entanto, que outros espaços curriculares precisam ser identificados para que as lacunas relativas à dimensão epistemológica sejam preenchidas.

\section{Referências}

ABD-EL-KHALICK, F.; LEDERMAN, N. G. Improving science teachers'conceptions of nature of science: a critical review of literature. International Journal of Science Education, Londres, v. 22, n. 7, p. 665-701, 2000.

ACEVEDO, J. A. et al. Mitos da didática das ciências acerca dos motivos para incluir a natureza da ciência no ensino de ciências. Ciência \& Educação, Bauru, v. 11, n. 1, p. 1-15, 2005.

BACHELARD, G. A filosofia do não: a filosofia do novo espírito científico. 5. ed. Trad. Joaquim José Moura Ramos. Lisboa: Editorial Presença, 1991. 1977.

O racionalismo aplicado. 5. ed. Trad. Nathanael Caixeiro. Rio de Janeiro: Zahar,

BACON, F. Novum organum ou verdadeiras indicações acerca da interpretação da natureza. Trad. José A. R. de Andrade. São Paulo: Abril Cultural, 1984. (Coleção Os Pensadores).

BOGDAN, R. C.; BIKLEN, S. K. Investigação qualitativa em educação: uma introdução à teoria e aos métodos. Trad. Maria J. Alvarez; Sara B. dos Santos; Telmo M. Baptista. Porto: Porto Editora, 1994. (Coleção Ciências da Educação).

CHALMERS, A. F. O que é ciência afinal ? 1. ed. Trad. Raul Fiker. São Paulo: Brasiliense, 1995.

FEYERABEND, P. Contra o método: esboço de uma teoria anarquista do conhecimento. 3. ed. Trad. Octanny S. da Mota e Leonidas Hegenberg. Rio de Janeiro: Francisco Alves, 1989. 
Oki, M. C. M.; Moradillo, E. F.

FREIRE JUNIOR, O. A relevância da filosofia e da história da ciência para o ensino de ciência. In: SILVA FILHO, W. J. (Org.). Epistemologia e ensino de ciências. Salvador: Arcádia, 2002. p. 13-30.

GAGLIARDI, R. Como utilizar la historia de las ciencias en la enseñanza de las ciencias. Enseñanza de las Ciencias, Barcelona, v. 6, n. 3, p. 291-296, 1988.

GALAGOVSKY, L.; ADÚRIZ-BRAVO, A. Modelos y analogias en la enseñanza de las ciencias naturales. El concepto de modelo didáctico analógico. Enseñanza de las Ciencias, Barcelona, v. 19, n. 2, p. 231-242, 2001.

GIERE, R. How models are used to represent reality. Philosophy of Science, Baltimore (USA), n. 71, p. 742-752, 2004.

GILBERT, J. K. Model building and a definition of science. Journal of Research in Science Teaching, Hoboken, Nova York, n. 28, p. 73-79, 1991.

GIL-PÉREZ, D. et al. Para uma imagem não deformada do trabalho científico. Ciência $\boldsymbol{\&}$ Educação, Bauru, v. 7, n. 2, p. 125-153, 2001.

GOLDFARB, A. M. A. Da Alquimia à Química. 1. ed. São Paulo: Nova Stella/Edusp, 1987.

HANSON, N. R. Observação e interpretação. In: MORGENBESSER, S. (Org.). Filosofia da Ciência. São Paulo: Cultrix, 1975. p. 128-136.

HARRES, J. B. S. Uma revisão de pesquisas nas concepções de professores sobre a natureza da ciência e suas implicações para o ensino. Investigações em Ensino de Ciências, Porto Alegre, v. 4, n. 3, 1999. Disponível em: <http://www.if.ufrgs.br/public/ensino>.

Acesso em: 07 mai. 2003.

HODSON, D. Philosophy of Science, science and science education. Studies in Science Education, Leeds, Inglaterra, n. 12, p. 25-57, 1985.

HOLTON, G. The goals for Science Teaching. In: BROWN, S. C.; CLARKE, N.; TIOMNO, J. (Eds.). Why teach Physics? Massachusetts: The M.I.T. Press, 1963. p. 27-44.

JUSTI, R.; GILBERT, J. K. History and philosophy of science through models: some challenges in the case of 'the atom'. International Journal Science Education, Londres, v. 22, n. 9, p. 993-1009, 2000.

KUHN, T. A estrutura das revoluções científicas. 4. ed. Trad. Beatriz V. Boeira e Nelson Boeira. São Paulo: Perspectiva, 1996.

LAVILLE, C.; DIONNE, J. A construção do saber: manual de metodologia da pesquisa em ciências humanas. Trad. Heloísa Monteiro e Francisco Settineri. Belo Horizonte: Editora da UFMG, 1999.

LEDERMAN, N. G. Students' and teachers' conceptions of nature of science: a review of the research. Journal of Research in Science Teaching, Nova York, n. 29, p. 331-359, 1992. 
O ensino de história da Química: ...

LEITE, L. History of Science in Science Education: development and validation of checklist for analysing the historical content of science textbooks. Science $\boldsymbol{\&}$ Education, Dordrecht, Holanda, v. 11, n. 4, p. 333-359, 2002.

LOSEE, J. Introdução histórica à Filosofia da Ciência. 1. ed. Lisboa: Terramar, 1998.

LUFFIEGO, M. et al. Epistemologia, caos y enseñanza de lãs ciências. Ensenanza de las Ciencias, Barcelona, v. 12, n. 1, p. 89-96, 1994.

MATTHEWS, M. R. History, Philosophy and Science Teaching: what can be done in an undergraduate course? Studies in Philosophy and Education, Dordrecht, Holanda, n. 10, p. 93-97, 1990.

Science teaching: the role of History and Philosophy of Science. New York: Routledge, 1994.

McCOMAS, W. E.; ALMAZROA, H.; CLOUGH, M. P. The nature of science in science education: an introduction. Science \& Education, Hoboken, New Jersey, USA, n. 7, p. 511-532, 1998.

MORAES, R. Análise de conteúdo. Revista Educação, Porto Alegre, v. 22, n. 37, p. 7-32, 1999.

MOREIRA, M. A. Sobre o ensino do método científico. Caderno Catarinense de Ensino de Física, Florianópolis, v. 10, n. 1, p. 108-117, 1993.

NIAZ, M. How important are the laws of definite and multiple proportions in chemistry and teaching chemistry? A history and philosophy of science perspective. Science $\boldsymbol{\&}$ Education, Dordrecht, Holanda, n. 10, p. 243-266, 2001.

OKI, M. C. M. A História da Química possibilitando o conhecimento da natureza da ciência e uma abordagem contextualizada de conceitos químicos: um estudo de caso numa disciplina do curso de Química da UFBA. 2006. 430f. Tese (Doutorado em Educação) - Faculdade de Educação da Universidade Federal da Bahia, Salvador, 2006.

PAIXÃO, F.; CACHAPUZ, A. Mudança na prática de ensino da Química pela formação dos professores em História e Filosofia das Ciências. Química Nova na Escola, Belo Horizonte, n. 18, p. 31-36, 2003.

POPPER, K. A lógica da pesquisa científica. Trad. Leonidas Hegenberg e Octanny Silveira da Mota. São Paulo: Cultrix/Edusp, 2001.

RUTHERFORD, F. J.; AHLGREN, A. Ciência para todos. Trad. Catarina C. Martins. Lisboa: Editora Gradiva, 1995.

SALMON, W. C. Logical empiricism. In: NEWTON-SMITH, W. H. (Org.) A companion to the philosophy of science. Oxford: Blackwell, 2000. p. 233-242.

SOLBES, J.; TRAVERS, M. La utilización de la Historia de las Ciencias en la Enseñanza de la Física e la Química. Enseñanza de las Ciencias, Barcelona, v. 14, n. 1, p. 103-112, 1996. 
Oki, M. C. M.; Moradillo, E. F.

TRIVIÑOS, A. N. S. Introdução à pesquisa em ciências sociais: a pesquisa qualitativa em educação. São Paulo: Atlas, 1987.

WANG, H. A.; MARSH, D. D. Science instruction with a humanistic twist: teachers' perception and practice in using the History of Science in their classrooms. Science $\boldsymbol{\&}$ Education, Dordrecht, Holanda, n. 11, p. 169-189, 2002.

WORTMANN, M. L. C. É possível articular a Epistemologia, a História da Ciência e a Didática no ensino científico? Episteme, Porto Alegre, v. 1, n. 1, p. 59-72, 1996.

Artigo recebido em dezembro de 2006 e aceito em julho de 2007. 